\title{
Local Circuits and Ocular Dominance Columns in Monkey Striate Cortex
}

\author{
Lawrence C. Katz, Charles D. Gilbert, and Torsten N. Wiesel \\ Laboratory of Neurobiology, The Rockefeller University, New York, New York 10021
}

The relationships between ocular dominance columns and intrinsic cortical circuitry were examined in brain slices prepared from the striate cortex of macaques. Ocular dominance columns in layer $4 \mathrm{C} \beta$ were visualized in vitro following anterograde transport of rhodamine injected into the lateral geniculate nucleus in vivo. The axonal and dendritic arborizations of individual layer $4 C \boldsymbol{B}$ cells were revealed by intracellular fluorescent dye injections.

Both qualitative observations and quantitative analysis showed that the dendrites of cells close to borders remained preferentially, although not absolutely, in the "home" column (the column containing the cell body). Thus, the segregated pattern of afferent input appears to have considerable influence on the pattern of dendritic arbors. Similarly, while axon collaterals within layer $4 \mathrm{C} \beta$ could cross into the adjacent column, their limited lateral spread produced arbors that remained primarily within the home column. The terminal arbors of collaterals that travelled from layer $4 \mathrm{C} \beta$ to layer 3 had a larger lateral spread, and the termination pattern appeared to be independent of column borders. Thus, our observations indicate that, while the course of many layer $4 \mathrm{C} \beta$ dendrites appears to be guided by columnar boundaries as defined by geniculate afferents, there exist morphological substrates for intercolumnar interactions even between $4 \mathrm{C} \beta$ cells. Intercolumnar interactions are seen more commonly in layer 3, however, where larger, denser axon arbors originating from $4 \mathrm{C} \beta$ cells can freely cross ocular dominance column boundaries.

A persistent issue in studies of visual cortical organization is the relationship between intrinsic microcircuits and cortical functional architecture, as exemplified by orientation and ocular dominance columns (e.g., Gilbert and Wiesel, 1979, 1983). In the primary visual cortex of Old World primates, geniculocortical afferents are rigidly segregated into alternating eye-specific bands in layer $4 \mathrm{C}$, forming the anatomical basis of the physiologically observed ocular dominance columns. This system of ocular dominance columns represents one of the clearest

\footnotetext{
Received July 18, 1988; revised Sept. 15, 1988; accepted Sept. 16, 1988.

We wish to thank J. Powzyk for her assistance in drawing cells, P. Peirce for expert photographic assistance, and D. Iarovici for helpful comments on the manuscript. L.C.K. is a Lucille P. Markey Scholar, and this work was supported in part by a grant from the L.P. Markey Charitable Trust. C.D.G. was supported by NSF grants BNS 8615935 and BNS 8351738 and an award from the Rita Allen Foundation. Also supported by NIH grants RO1 EY 05253 and Javits Center Grant 1P01 NS 22789 to T.N.W.

Correspondence should be addressed to Lawrence C. Katz, Laboratory of Neurobiology, Box 138, The Rockefeller University, 1230 York Avenue, New York, NY 10021.

Copyright (C) 1989 Society for Neuroscience $0270-6474 / 89 / 041389-11 \$ 02.00 / 0$
}

examples of a distinct functional architecture within the cortex. Neurons within layer $4 \mathrm{C}$ are, according to available physiological evidence (Hubel and Wiesel, 1968; Blasdel and Fitzpatrick, 1984), almost exclusively monocular. Within the supragranular layers cells are binocular, a response property that must be generated by connections between the subdivisions of layer $4 \mathrm{C}$ and these layers. Binocular interactions are important for analyses of position in depth and 3-dimensional structure. The striate cortex represents the first stage at which interactions between the 2 eyes can take place at the level of individual cells.

Although several of the connections that might mediate these interactions have been described (Lund and Boothe, 1975; Fitzpatrick et al., 1985), nothing is known about the relationships between axons and dendrites of individual layer $4 \mathrm{C} \beta$ neurons and the pattern of ocular dominance columns. This is due in part to the difficulty of simultaneously visualizing both afferents and the detailed morphology of postsynaptic cells. We combined lateral geniculate nucleus injections of an anterogradely transported fluorescent tracer with brain slice techniques to visualize in vitro the system of ocular dominance columns. Subsequent intracellular injections of cells in layer $4 \mathrm{C} \beta$, with a second fluorescent dye, allowed us to directly relate their dendritic and axonals arbors to the system of ocular dominance columns. Some of these results have been reported in abstract form (Katz et al., 1986).

\section{Materials and Methods}

A total of 6 adult macaque monkeys (2.3-3 kg) of both sexes were used. Animals were initially anesthetized with Ketamine $(20 \mathrm{mg} / \mathrm{kg}$, i.m.), maintained on a continuous infusion of sodium pentothal $(2 \mathrm{mg} / \mathrm{kg} / \mathrm{hr}$, i.p.), paralyzed (vecuronium bromide, $0.1 \mathrm{mg} / \mathrm{kg} / \mathrm{hr}, \mathrm{i} . \mathrm{v}$.), and artificially respirated. Heartbeat, EEG, body temperature, and expired $\mathrm{CO}_{2}$ were continuously monitored, and sterile technique was used during all recovery surgery. The eyes were focused onto a tangent screen using contact lenses, and the fovea of each eye was then projected onto this screen. The lateral geniculate nucleus was located using standard extracellular recordings with tungsten microelectrodes; receptive field positions of geniculate cells were mapped using small spots of light projected onto the tangent screen. In order to insure labeling on the operculum, we located the parafoveal region of the LGN. Subsequently, the tungsten electrode was replaced with a $1 \mu \mathrm{l}$ Hamilton syringe, insulated except at the very tip. Using background hash as a guide, the electrode tip was placed between layers 2 and 3 of the geniculate, which both receive input from the ipsilateral eye. We usually made two $0.5 \mu \mathrm{l}$ tracer injections, spaced about $500 \mu \mathrm{m}$ apart, in each electrode track. Two to four injection tracks, spaced at least $1.5 \mathrm{~mm}$ apart, were made in each geniculate. Ocular dominance columns were fluorescently labeled with an anterograde tracer: freshly prepared $5 \%$ tetramethylrhodamine isothiocyanate, isomer R (TRITC) (Sigma) dissolved in dimethylsulfoxide. This tracer has been used previously to label retinal axons in tissue culture (Thanos and Bonhoeffer, 1983) and retinotectal afferents in frogs (Katz and Constantine-Paton, 1988).

Each injected animal was used for 2 slice experiments, after a survival 


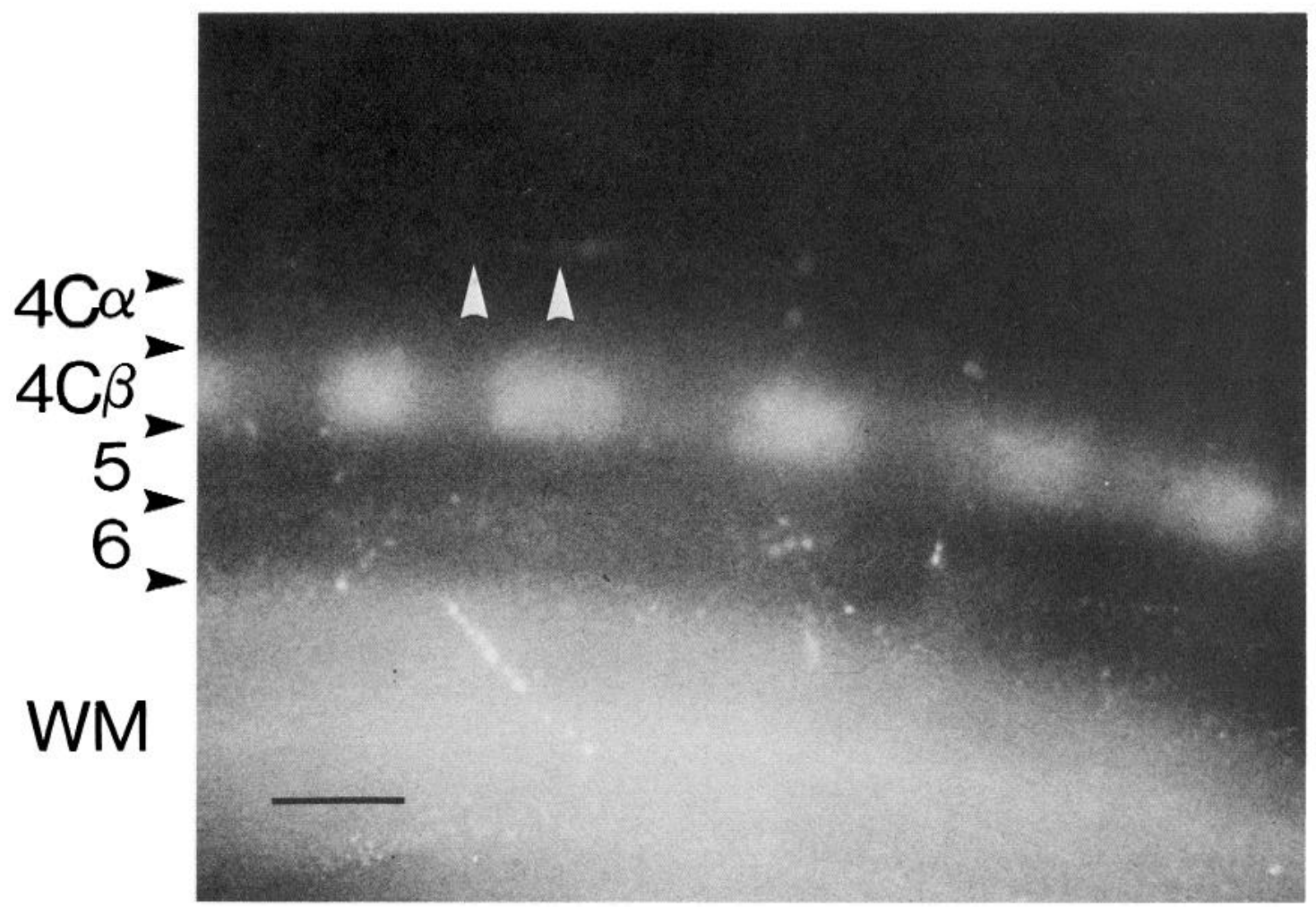

Figure 1. Rhodamine-labeled ocular dominance columns in a coronal brain slice of monkey striate cortex. This micrograph of a living, $400-\mu \mathrm{m}$ thick brain slice, under rhodamine excitation, shows clear labeling of individual ocular dominance columns (white) restricted to layer $4 \mathrm{C} \beta$. The large white area at the bottom is the cortical white matter, filled with rhodamine-labeled axons. Arrows indicate the lower border of layer 4A. Scale bar, $500 \mu \mathrm{m}$.

time of at least 2 weeks before the first experiment. The striate cortex of one hemisphere was used in each individual experiment. In the first slice experiment, the animal was anesthetized with pentathol and prepared for sterile surgery. A trephine was used to open a 2-cm-diameter hole over one hemisphere, and most of the operculum was removed by appropriate scalpel cuts and undercutting the cortex with a sharpened spatula. The excised piece (about $2-3 \mathrm{~cm}^{2}$ ) was immediately placed in cool $\left(10-15^{\circ} \mathrm{C}\right)$ oxygenated artificial CSF and removed from the surgery room to the brain slicing set-up. Both the dura and the piece of cranium removed by the trephine were sutured back in place. In the terminal experiment, similar procedures were used (under nonsterile conditions); after removal of the operculum, the animal was perfused $(0.1 \mathrm{M}$ phosphate buffer rinse, $\mathrm{pH} 7.4$, followed by $4 \%$ paraformaldehyde in $0.1 \mathrm{M}$ phosphate, $\mathrm{pH}$ 7.4). A block of brain containing the LGN was subsequently removed, sunk in $30 \%$ sucrose, and sectioned at $40 \mu \mathrm{m}$ on a freezing microtome. Sections were mounted on slides and counterstained with cresyl violet to verify the laminar position of injections.

The preparation, maintenance, and intracellular injection of neurons in brain slices followed procedures previously described in detail (Katz, 1987; Katz and Constantine-Paton, 1988). Briefly, after removing the pia, the excised piece was cut into 3 strips, each about $0.5 \mathrm{~cm}$ wide and $1.5 \mathrm{~cm}$ long. These were sliced coronally (i.e., perpendicular to the lunate gyrus) at $400 \mu \mathrm{m}$ using a special brain slicer that can cut up to 60 slices simultaneously. Slices were maintained at $33^{\circ} \mathrm{C}$ in conventional hippocampal slice chambers, in standard artificial cerebrospinal fluid, under a $95 \% \mathrm{O}_{2}, 5 \% \mathrm{CO}_{2}$ atmosphere, where they remained viable for up to $12 \mathrm{hr}$. Individual slices were transferred to a miniature chamber on the stage of an epifluorescence-equipped compound microscope. With a $10 \times$ objective (Wild, N.A. 0.45 ), ocular dominance columns were clearly visible as sharply defined patches of TRITC label (Fig. 1). Individual layer $4 \mathrm{C} \beta$ neurons were subsequently impaled and injected with Lucifer yellow, fixed in paraformaldehyde ( $4 \%$ in $0.1 \mathrm{M}$ phosphate buffer, pH 7.4), sectioned (at $40 \mu \mathrm{m}$ ), and mounted on slides for photography and camera lucida reconstruction.

\section{Results}

In order to understand better how, at the level of individual postsynaptic cells, inputs from the 2 eyes are segregated within layer $4 \mathrm{C}$, we focused on intracellularly injected cells lying at or near the borders between rhodamine-labeled ocular dominance columns. Although we injected rhodamine between geniculate layers 2 and 3 , which should have labeled both $4 \mathrm{C} \alpha$ and $4 \mathrm{C} \beta$, the anterograde labeling in $4 \mathrm{C} \beta$ was generally much sharper, more consistent, and brighter. This was probably due to reflux of the injected rhodamine solution up the pipette track. Consequently, cells were injected primarily in layer $4 \mathrm{C} \beta$, and the observations presented here deal almost exclusively with the organization of layer $4 \mathrm{C} \beta$ cells.

Ocular dominance column borders within layer $4 \mathrm{C} \beta$, as visualized by the rhodamine label, were extremely sharp even in vitro (Fig. 1). In fixed, cleared, and sectioned tissue the transition between dense label and sparse label occurred in less than 20 $\mu \mathrm{m}$. The slightly higher than background labeling between columns probably reflects some leakage of label into laminae of the other eye. Anterograde labeling was also present in layer 4A, where it exhibited the characteristic "honeycomb" appearance previously described (Hendrickson et al., 1978; Blasdel and Lund, 1983). Compared with slices prepared with identical methods from cat visual cortex, obtaining satisfactory intracellular impalements and fills in the monkey cortex was considerably more difficult. Part of this difficulty can be explained by the small size of neurons in layer $4 \mathrm{C} \beta$, but the difficulty extended to other 
A

B

$4 \mathrm{C} \alpha$
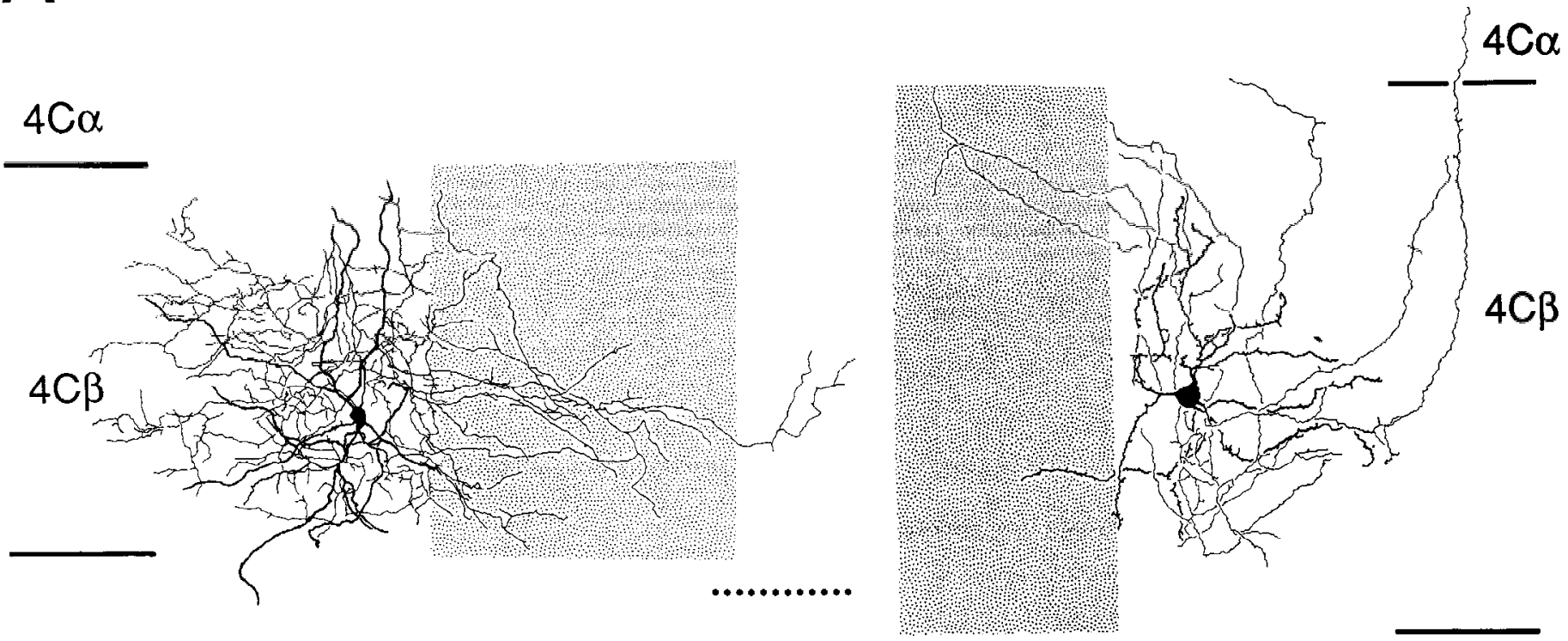

Figure 2. Lucifer yellow-filled neurons in layer $4 \mathrm{C} \beta$ with clear biases away from column borders. $A$, A spine-free stellate cell whose dendrites do not cross the border between 2 columns but whose axon collaterals clearly do. Stippled area represents only a portion of the adjacent column; this cell's axons cross into, but do not traverse, the adjacent column. $B$, A sparsely spined stellate cell with dendrites that preferentially arborize within the home column. Two collaterals of this cell penetrate into the adjacent column. Scale bar (dotted line), $100 \mu \mathrm{m}$.

layers as well. Monkey cortex may be more traumatized by slicing than cat (or rat) cortex. The poorer health of the slices was probably not caused by the TRITC labeling, since unlabeled cortices had similar problems. Intracellularly impaled neurons had action potentials ranging from 25 to $50 \mathrm{mV}$; outside of layer $4 \mathrm{C} \beta$ they were larger. Because of their small size, lower currents than usual $(0.2-0.7 \mathrm{nA}, 1-3 \mathrm{~min})$ were used for the iontophoresis of Lucifer yellow. Despite the reduced viability, 10-20 wellfilled neurons were obtained in each experiment. About half were located in layer $4 \mathrm{C} \beta$, the rest in other layers (cells located outside layer 4 will not be described in this report). Thus, a total of 40 intracellularly stained cells in various locations relative to the ocular dominance bands in layer $4 \mathrm{C} \beta$ was obtained; camera lucida drawings were made of 22 of these. These drawings were used to assess whether individual dendrites or axons of layer $4 \mathrm{C} \beta$ cells reflected the abrupt discontinuity in the pattern of afferent input.

\section{Dendritic bias at borders}

An example of a layer $4 \mathrm{C} \beta$ cell, close to a column border, is shown in Figure $2 A$. This cell was a spine-free neuron, located about $50 \mu \mathrm{m}$ from the border. The dendritic arbor had a pronounced asymmetry: Dendrites on the side facing the border appeared to either terminate at or bend away from the border. Similar behavior was seen in spiny neurons, like the one in Figure $2 B$. In contrast, cells near the center of the columns (Fig. 7) appeared to have more symmetric arbors. However, not all cells had dendrites that suggested avoidance of the border. For example, the cell in Figure $5 C$ (a spiny cell with axons in layer 3 ) seemed to have roughly symmetrical arbors directed towards and away from the border. In order to clarify the behavior of the population, we constructed a "bias index" for cells at various distances from the column borders. A series of equally spaced concentric rings was drawn around the cell body ( $20 \mu \mathrm{m}$ spacing between rings); the rings were bisected by a line through the cell body running parallel to the column border. This divided the dendritic arbor into 2 halves: one facing towards the border, the other facing away. At each distance from the cell body, the number of intersections of dendrites with each hemicircle was counted. A bias index was constructed by the ratio of the total number of intersections away form the border to the number of intersections towards the border. A bias index of 2, for example, meant that a cell had approximately twice as many dendrites directed away from the border as towards the border.

Twenty-two cells, including both spiny and nonspiny, were analyzed, and the results are shown in Figure 3 . All cells within $50 \mu \mathrm{m}$, and most cells within $100 \mu \mathrm{m}$ of the border had bias indices greater than 1 ; only a single cell out of 8 located more than $100 \mu \mathrm{m}$ from the border had a pronounced bias. In both the present study and previous Golgi studies (Lund and Boothe, 1975) stellate cells in layer $4 C \beta$ have quite uniform radii of about $100 \mu \mathrm{m}$. Therefore, it appears that cells within one dendritic radius of an ocular dominance column border have the shape of their dendrites modified by the presence of an abrupt discontinuity in the source of afferent input.

We also observed 2 examples of cells with somata almost exactly on the border between columns. Both had sparsely spiny dendrites and were located in the middle depths of layer $4 \mathrm{C} \beta$ (Fig. 4). Their axonal morphology resembled that of other spiny cells in the layer, rather than that of smooth stellate cells. Based on the results for cclls ncar column boundarics, onc might predict that cells on the border would be strongly biased and have all their dendrites in one column or the other. In these $2 \mathrm{ex}$ amples, however, the opposite occurred: The cells had roughly equivalent arbors in both columns. This suggests that these cells can receive input from both eyes, and could be binocular neurons (these cells were not included in Fig. 3). 

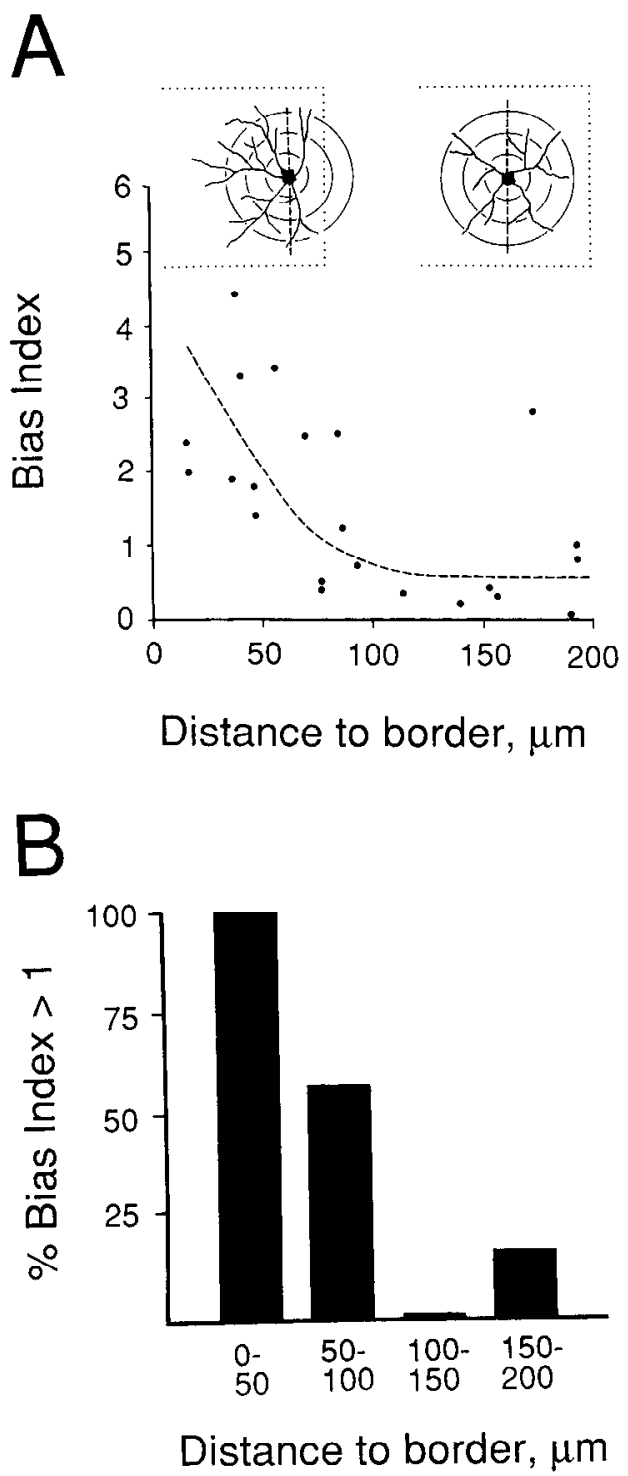

Figure 3. Dendritic bias of cells at various distances from ocular dominance column borders. $A$, Relationship between "bias index" (computed as the ratio of number of branch intersections away from versus towards a border) and distance from the border. The insets above the graph illustrate both the method of computing bias indices and examples of highly biased and unbiased arbors. $B$, Histogram of the relative percentages of biased cells at various distances from the column borders. All cells within $50 \mu \mathrm{m}$, and most within $100 \mu \mathrm{m}$, show a pronounced bias in their dendritic arbors away from a column boundary.

\section{Relationships of axonal arbors to column borders}

Ten of the 22 filled cells analyzed in detail (by camera lucida drawings) corresponded to the well-described spiny granule neurons of layer 4C $\beta$ (Cajal, 1911; Lund, 1973, 1984). These cells had 1-3 recurrent axons that initially descended a short distance from the soma, then turned abruptly and headed towards the pia. Short horizontal and vertical collaterals $(<200 \mu \mathrm{m}$ long) were abundant in layer $4 \mathrm{C} \beta$ and absent from layers $4 \mathrm{C} \alpha, 4 \mathrm{~B}$, and $4 \mathrm{~A}$ (Figs. 5,6). Within layer $3 \mathrm{~B}$, the recurrent collaterals branched into a spray of horizontally directed branches, which, in the best-filled cases (e.g., Fig. 5, $a, b$ ), extended for up to 300 $\mu \mathrm{m}$ on either side of the main collaterals.

Within layer $4 \mathrm{C} \beta$, axon collaterals generally remained in the immediate vicinity of the cell's dendritic arbor. Unlike the dendrites, however, the presence of a columnar boundary did not seem to influence either the course or number of axon collaterals directed towards the boundary. This was true of collaterals within $3 \mathrm{~B}$ as well. Instead, they seemed to freely cross the border and occasionally terminate within the adjacent column (Fig. 5). We did not see any cases in which a collateral originating from one eye column traversed the adjacent column to terminate in another same-eye column. Of the 10 reconstructed granule cells, 7 also had terminals within the adjacent eye column; in the other 3 , the layer 4 axons remained within the home column (e.g., Figs. $5 d, 6 a$ ). Spiny stellate cells presumably make excitatory synapses; thus, these connections may underlie facilitory interactions between different eye columns.

Nine of the other reconstructed cells had medium to sparsely spiny dendrites that had the same dendritic radius as the granule cells. Most of these cells had axons that remained within layer $4 \mathrm{C} \beta$ (Figs. $6, c, d ; 7, a, b$ ). Some of these cells may have had axons like the granule cells described above but were incompletely filled or truncated in the slicing process. The axons of all these cells behaved similarly to the granule cells described above in that most freely crossed the border between adjacent columns.

Three cells with spine-free dendrites were analyzed as well. Two of these were near column borders (one of these is shown in Fig. 2). In both cases, it is clear that while the dendrites are restricted to the "home" column, the axons of this cell freely cross into the adjacent column. Since spine-free cells are GABAergic and presumably inhibitory, these cells provide evidence of a direct inhibitory interaction between adjacent columns. Neither of the 2 spine-free cells sent axons into the next sameeye column. The third spine-free cell was located in the middle of a column (Fig. $7 d$ ) and had a dense, locally arborizing axon almost exclusively within layer $4 \mathrm{C} \beta$, with a fine collateral to layer 5 .

Although the emphasis of this study was on the cells of layer $4 C \beta$, one spiny stellate cell was recovered from the middle of layer $4 \mathrm{C} \alpha$. As noted in previous Golgi descriptions (Lund, 1973, 1984), the dendritic arbor of this cell was somewhat larger than that of layer $4 \mathrm{C} \beta$ cells. This cell (Fig. 8) was not close enough to an ocular dominance column border to determine whether it showed behavior similar to $4 \mathrm{C} \beta$ cells. However, its well-filled axonal arbor ascended through $4 \mathrm{C} \alpha$ and branched extensively within $4 \mathrm{~A}$ and $3 \mathrm{~B}$.

\section{A possible subdivision of layer $4 C$}

In several experiments, the rhodamine injections into the LGN labeled both $4 \mathrm{C} \alpha$ and $4 \mathrm{C} \beta$. In these slices we were surprised to observe that labeling was not continuous throughout the thickness of layer 4C. As Figure 9 shows, these injections revealed a narrow but prominent gap, about $50 \mu \mathrm{m}$ wide, separating layers $4 \mathrm{C} \alpha$ and $4 \mathrm{C} \beta$. This gap, which presumably represents a geniculate afferent-sparse zone, was much clearer in the thick slices than in sectioned material. This could explain why it was not detected in the autoradiographic material of earlier studies $(\mathrm{Hu}-$ bel et al., 1977; Hendrickson et al., 1978). A gap has been observed in near the base of layer $4 \mathrm{C} \beta$ in young (but not adult) monkeys when the striate cortex was reacted for cytochrome oxidase (Fitzpatrick et al., 1985) but seems to be located differently than the gap reported here. Unfortunately, no intracellularly stained neurons were recovered from within the gap. 
A

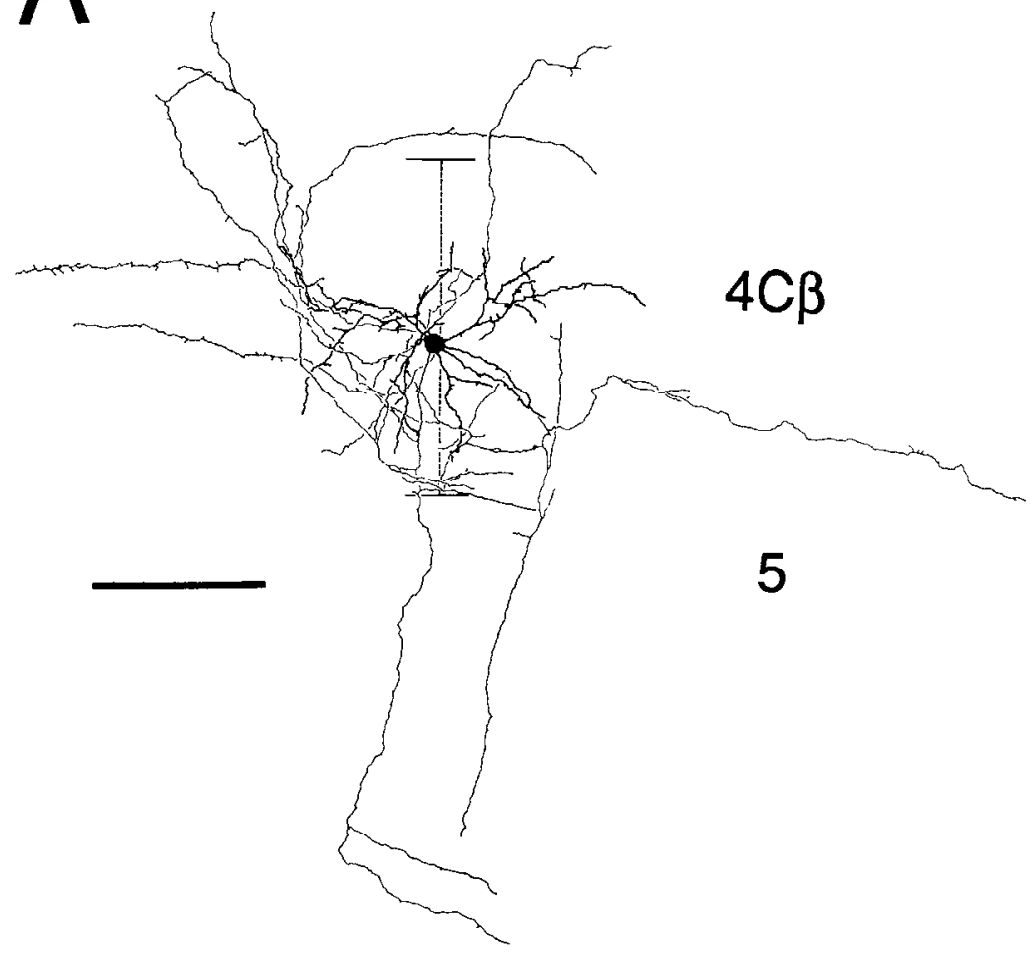

B
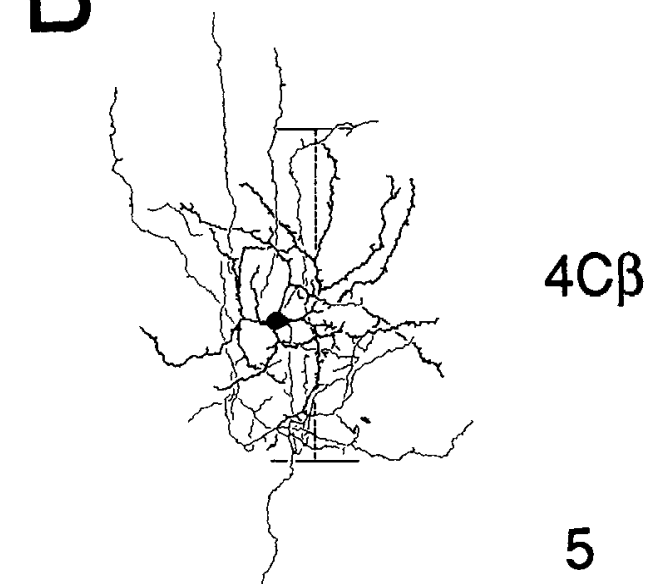

5

Figure 4. Cells on the border between 2 columns. A, This sparsely spined cell had a cell body that lay almost exactly on the boundary. Unlike most cells, its dendritic arbor was elongated horizontally rather than vertically. Two separate clumps of dendrites are in each column. This cell also had considerable axonal arbors in both columns. $B$, A second cell very close to a border. Like the cell in $A$, both dendrites and axons arborize in both columns. Scale bars, $100 \mu \mathrm{m}$.

\section{Discussion}

In these investigations, we have tried to relate a prominent feature of cortical architecture-the ocular dominance columns - to the intricacies of local neuronal circuits within layers 4 and 3 . Three features of the parvocellular pathway through layer $4 \mathrm{C} \beta$ emerge from this work: (1) Dendrites of cells in the primary afferent recipient zone do not passively accept whatever input happens to be present but are biased towards receiving input from one eye; (2) axons of excitatory cells within layer 4 provide a weak avenue for possible interactions between adjacent, different-eye columns; and (3) outside of layer 4, intrinsic axons of layer $4 \mathrm{C} \beta$ cells do not seem constrained by the borders imposed by the segregated afferents and should therefore permit intercolumn interactions.

\section{Dendritic responses to discontinuous afferent patterns}

Extracellular recordings (Hubel and Wiesel, 1968) established that the cells in layer $4 \mathrm{C}$ were almost exclusively monocular. Although a few binocular cells were noted, these were located in a narrow transition zone, and it was difficult in those studies to resolve single units unambiguously. How is monocularity maintained in layer 4 ? The strict segregation of geniculate afferents (Hubel and Wiesel, 1972; LeVay et al., 1980), coupled with the relatively restricted dendritic fields of layer 4 granule cells, could alone account for monocularity. However, despite their small (100 $\mu \mathrm{m}$ radius) dendritic fields, in a $500-\mu \mathrm{m}$-wide column, the dendrites of up to $40 \%$ of cells could confront a transition zone between one eye's input and the other. From extracellular recordings, it is clear that $40 \%$ of the cells in layer $4 \mathrm{C} \beta$ are not binocular in the sense that they generate spikes in response to input from either eye. No intracellular records from layer $4 \mathrm{C} \beta$ cells in vivo have been published; hence it is difficult to evaluate the degree of binocular synaptic input. Based on the anatomical results presented here, it appears that several mechanisms could maintain monocularity. The most obvious one is that dendrites seem biased away from the adjacent eye's inputs. Although this bias is not absolute, it could reduce the input from the other eye to a level below that which would generate impulses. A second mechanism for reinforcing monocularity could arise by cross-columnar inhibition. Although we observed only a small number of smooth stellate cells, they had a significant axonal arborization along the border region. If such cells directly contacted spiny stellate cells (for which we have no direct evidence), inhibitory inputs could prevent a spiny cell with binocular excitatory inputs from firing.

\section{Modifications of dendritic shape by afferent patterns}

The fact that dendrites of layer $4 \mathrm{C} \beta$ cells are biased away from the termination zone of afferents from the other eye implies that the pattern of afferent segregation has played a significant role in shaping the structure of the postsynaptic dendritic field of cortical neurons. This bias should be distinguished from other dendritic behavior at laminar borders. For example, in subdivisions of layer 4 of both tree shrew and macaque striate cortex, the dendrites of several varieties of cells are strictly confined to single sublaminae (Lund, 1984). In these cases, dendrites seem to distinguish between different types of inputs (parvo- or mag- 
Figure 5. Examples of spiny stellate cells within layer $4 \mathrm{C} \beta$ with collaterals to layer 3B. $A$, A spiny stellate cell close to a column boundary whose dendrites are biased away from the border. Within layer 4 , the cell has weak connections to both the home column and the adjacent column. The connection to layer $3 B$ is considerably denser than that to either layer 4 or layer 5 . $B$, A spiny stellate cell located about $100 \mu \mathrm{m}$ from a border. This cell also has weak connections within layer 4 , and a denser, more focused arborization within 3B. $C$, Two spiny stellate cells whose dendritic and axonal arbors show almost complete overlap. $D$, A spiny stellate cell with mostly local connections in the home column. The arbor in layer 3B is probably incomplctc. Scale bars, 100 $\mu \mathrm{m}$.
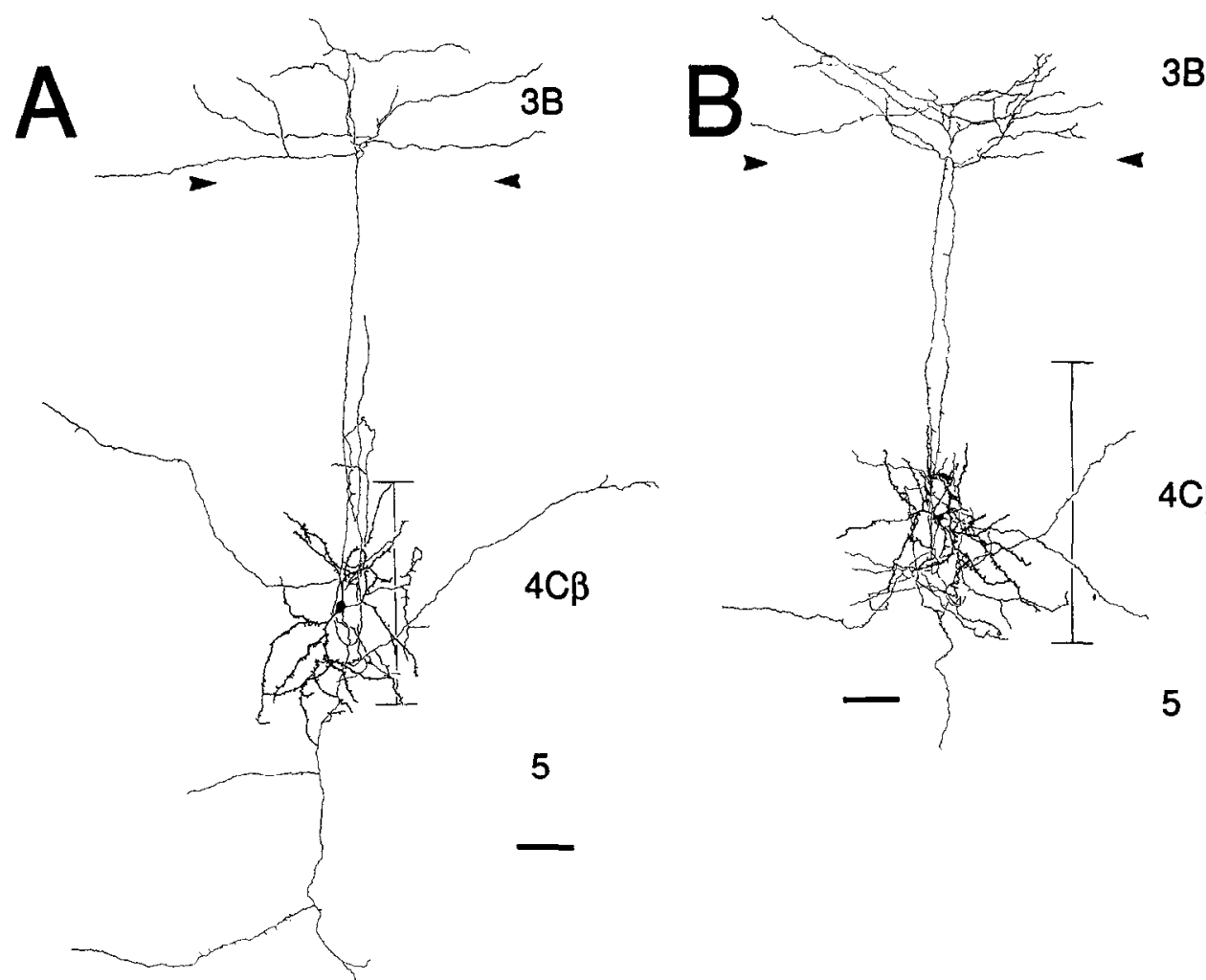

3B
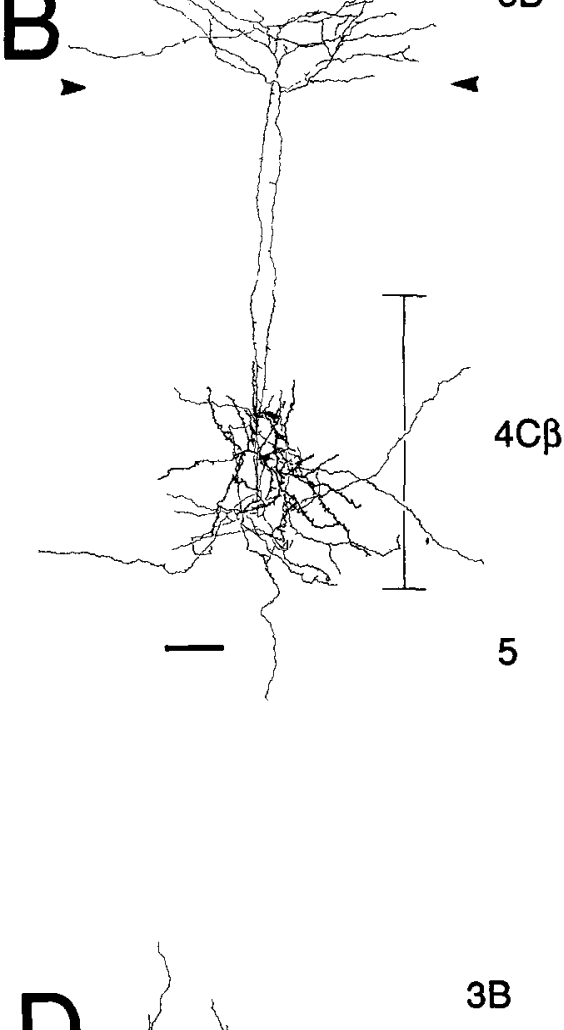

C

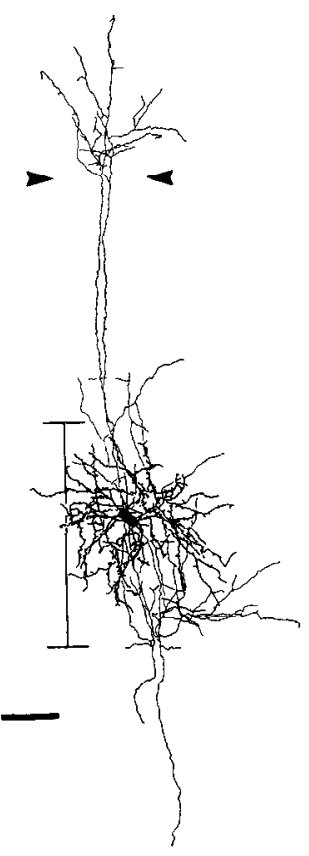

3B

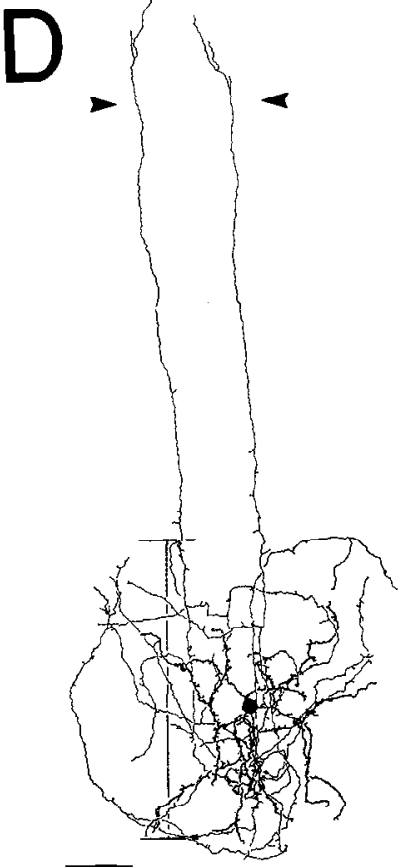

$4 \mathrm{C} \beta$ nocellular). The dendritic patterns described in this report, in contrast, reveal that dendrites can distinguish among parvocellular inputs within the same sublamina. While the asymmetries obscrved in this system are not as dramatic as the markedly skewed dendrites of cells in layer 4 of the somatosensory "barrel field" cortex in rodents (Harris and Woolsey, 1979; Steffen and Van der Loos, 1980), they resemble, to a remarkable degree, the kinds of alterations seen in the postsynaptic tectal neurons in 3-eyed frogs. When the pattern of tectal cell dendrites was related to the pattern of eye-specitic stripes in these animals, Katz and Constantine-Paton (1988) found that certain types of ncurons, cspecially those with small, highly branched dendritic arbors, would not cross the border between 2 eye termination zones. They also described cells, very close to stripe borders, with dendritic arbors in both eye termination zones. Although rare, cells with similar morphology were seen in the present 
study. In the frog, the border between 2 adjacent stripes represents an abrupt transition in the degree of correlated activity among afferent inputs. In the monkey, the border between columns is a zone within which visual field position undergoes its greatest change. In traversing a single ocular dominance column in layer $4 \mathrm{C} \beta$, a topography is clearly evident (Hubel and Wiesel, 1977). When the adjacent column is encountered, the cells near the border do not have visual field positions identical to the closest cells in the other column. Rather, they have visual fields closer to those in the center of the other column. Thus, in the monkey, there is likely to be a shift in the correlated activity among the afferents to a cell at a column border, such that these borders represent discontinuities in the correlation of incoming visual activity. This may be one cue utilized by the developing system to alter the pattern of dendrites so as to maximize the amount of correlated inputs a given cell receives. However, the cells very close to or on the border indicate that a single cell can potentially integrate the 2 temporally distinct inputs originating from each eye. For these cells, this might be accomplished by having each eye's input terminate on a spatially separate group of dendrites, such that within a local dendritic domain, afferent activity remained highly correlated. Sequestering each eye's input onto a separate local dendritic domain could produce the cells with separate groups of dendrites in each eye's column, but few if any branches that crossed from one column to another.

\section{Excitatory intralaminar axonal connections}

In addition to the inhibitory interactions within layer $4 \mathrm{C} \beta$, considerable axonal arborizations originated from spiny stellate cells. For the most part, these were confined to within 2 dendritic arbor radii of the cell body (about $200 \mu \mathrm{m}$ ). Most of these axons remained within the "home" column, providing only sparsc connections to adjacent columns. The patterns within layer 4 are in close agreement with those described using Golgi methods (Valverde, 1971; Lund, 1973, 1984), and contrast with the longdistance horizontal arbors observed in layer 4 in the cat (Gilbert and Wiesel, 1979; Martin and Whitteridge, 1984). The pattern of arbors within layer 4 also contrasts with the pattern of arbors of the same cells within layer $3 \mathrm{~b}$ (see below). Although intracellular staining in slices is subject to limitations, we believe we could have seen longer-distance connections had they existed. Since we were able to fill processes reaching to layer 3 that were over $500 \mu \mathrm{m}$ long, we should have been able to see processes of similar length in layer 4 , had they been present. Therefore, although we observed connections linking columns receiving inputs from different eyes, we never observed any excitatory or inhibitory connection linking columns receiving input from the same eye. This is also in agreement with the results of Fitzpatrick et al. (1985), who found that small HRP injections in layer $4 \mathrm{C} \beta$ only labeled terminals within about a $200 \mu \mathrm{m}$ radius.

\section{Excitatory interlaminar connections}

The cell type that we observed most commonly was a spiny stellate cell with 1-3 recurrent axon collaterals that ascended, unbranched, to terminate in a spray of collaterals in layer 3B. We detected no difference in the behavior of collaterals in layer $3 \mathrm{~B}$ as they encountered a column horder. In the best-filled cells, the largest lateral spread was about $150 \mu \mathrm{m}$ to either side of the cell body. This is similar to the results of Fitzpatrick et al.'s extracellular injections. This behavior, we believe, could also partly underlie the generation of the larger, binocular receptive

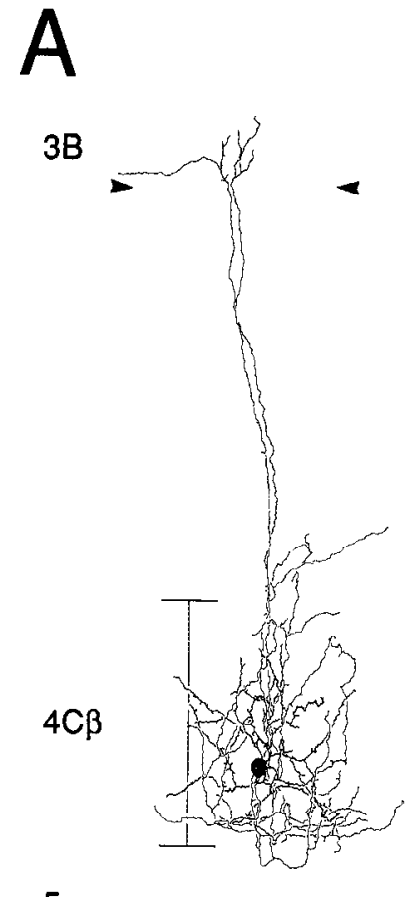

5

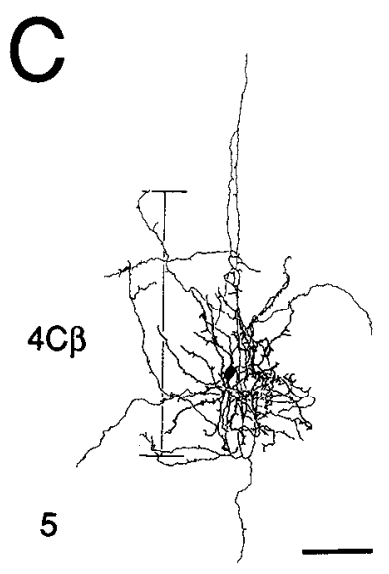

D

5
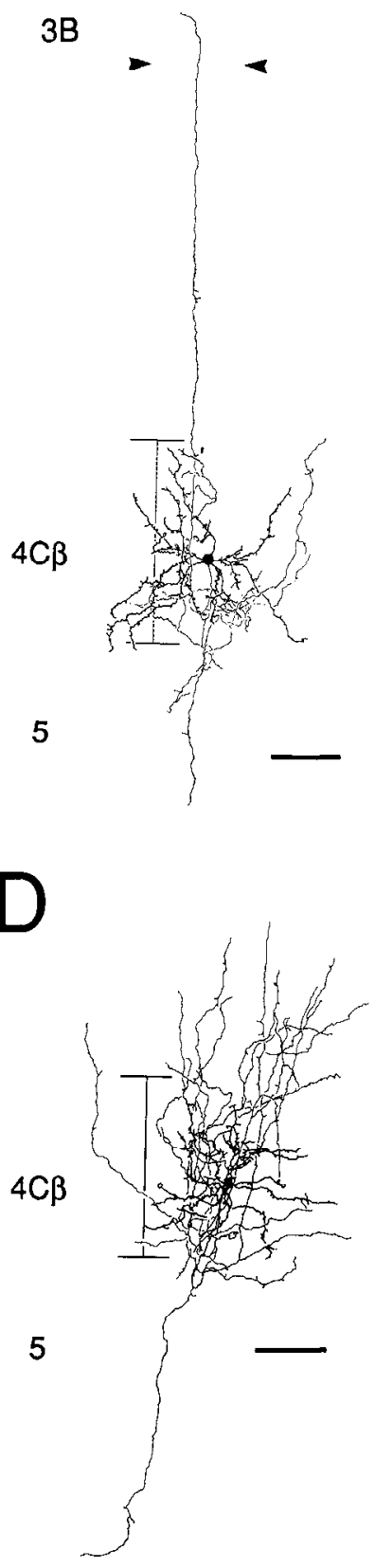

Figure 6. Spiny cells in layer $4 C \beta$. $A$, Spiny cell whose axons remain within the home column. $B$, Spiny cell whose dendrites cross into the adjacent column but whose axons remain within the home column. $C$ and $D$, Spiny cells with connections only within layer 4 . Scale bars, 100 $\mu \mathrm{m}$.

fields in the supragranular layers. Because the axons of layer $4 \mathrm{C} \beta$ cells can reach over $100 \mu \mathrm{m}$ into an adjacent column (from each side), layer 3B cells near column borders should receive considerable binocular input. Indeed, the ocular dominance profiles of individual cells recorded from tracks through the supraand infragranular layers (Hubel and Wiesel, 1977) show a clear tendency from monocularity towards binocularity as one approaches the edge of an ocular dominance column.

The behavior of collaterals within layer 3 contrasted sharply 


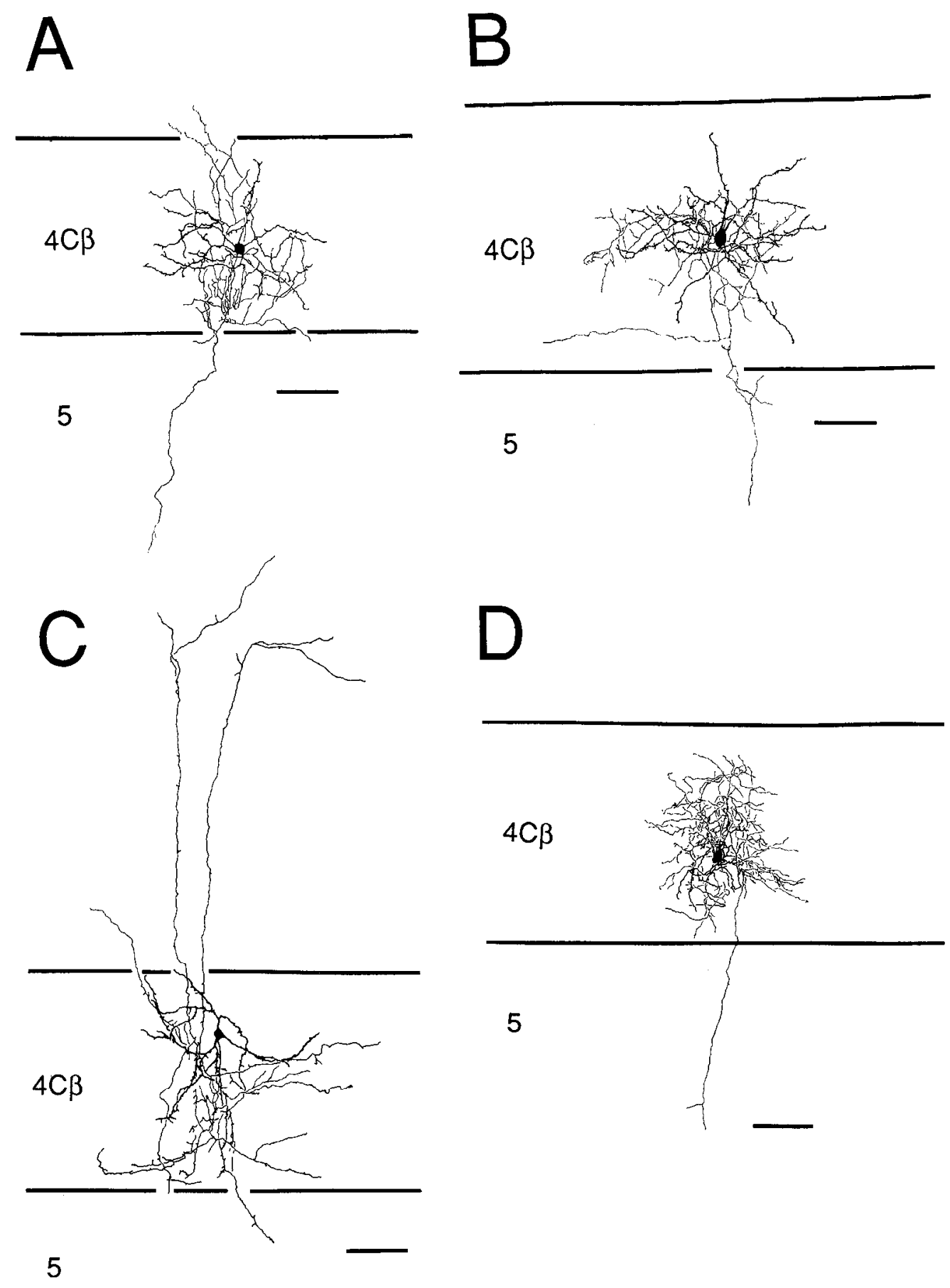

Figure 7. Sparsely spined and aspinous cells located in the center of columns. $A$ and $B$, Sparsely spined cells with connections within layer $4 \mathrm{C} \beta$ and to layer 5. Both had symmetrical dendrites. $C$, Sparsely spined cell with connection to layer 3B. $D$, Aspinous cell with dense local axonal arborization. Scale bars, $100 \mu \mathrm{m}$

with the behavior of the same cell's collaterals within layer $4 \mathrm{C} \beta$. While the connections within layer 4 were generally sparse and diffuse, the arbors in layer 3 were usually dense and focused. Thus, an individual cell might provide a relatively focused excitatory input to a given region of layer $3 \mathrm{~B}$ but provide only a diffuse and weak signal to corresponding points in layer 4 .

Although we had hoped to relate directly the pattern of these interlaminar connections to the pattern of cytochrome oxidase blobs in layer 3 , this proved to be impossible with the staining techniques employed. We found that the cytochrome oxidase histochemical reaction destroyed most of the fluorescence of Lucifer yellow stained cells. In other experiments we attempted to visualize the geniculate input to the blobs by injecting the interlaminar zones in the geniculate, but the anterograde rhodamine labeling was too faint and variable to give a reliable indication of blob positions. In all our stained cells with connections to layer 3B, however, including those in the center of ocular dominance columns, we did not observe any lateral displacement of the terminal axonal arbor. Thus, it appears, in agreement with physiological studies (Ts'o and Gilbert, 1988), that blobs receive input from the layer $4 C \beta$ cells directly beneath them; the same seems to be true for interblob regions (Michael, 1986). However, the spread of axonal arbors in layer 3 argues that cells underneath blobs could provide input to the interblob region as well as to the overlying blobs. The unencumbered spread of layer $4 \mathrm{C} \beta$ axons within layer 3 might therefore help 


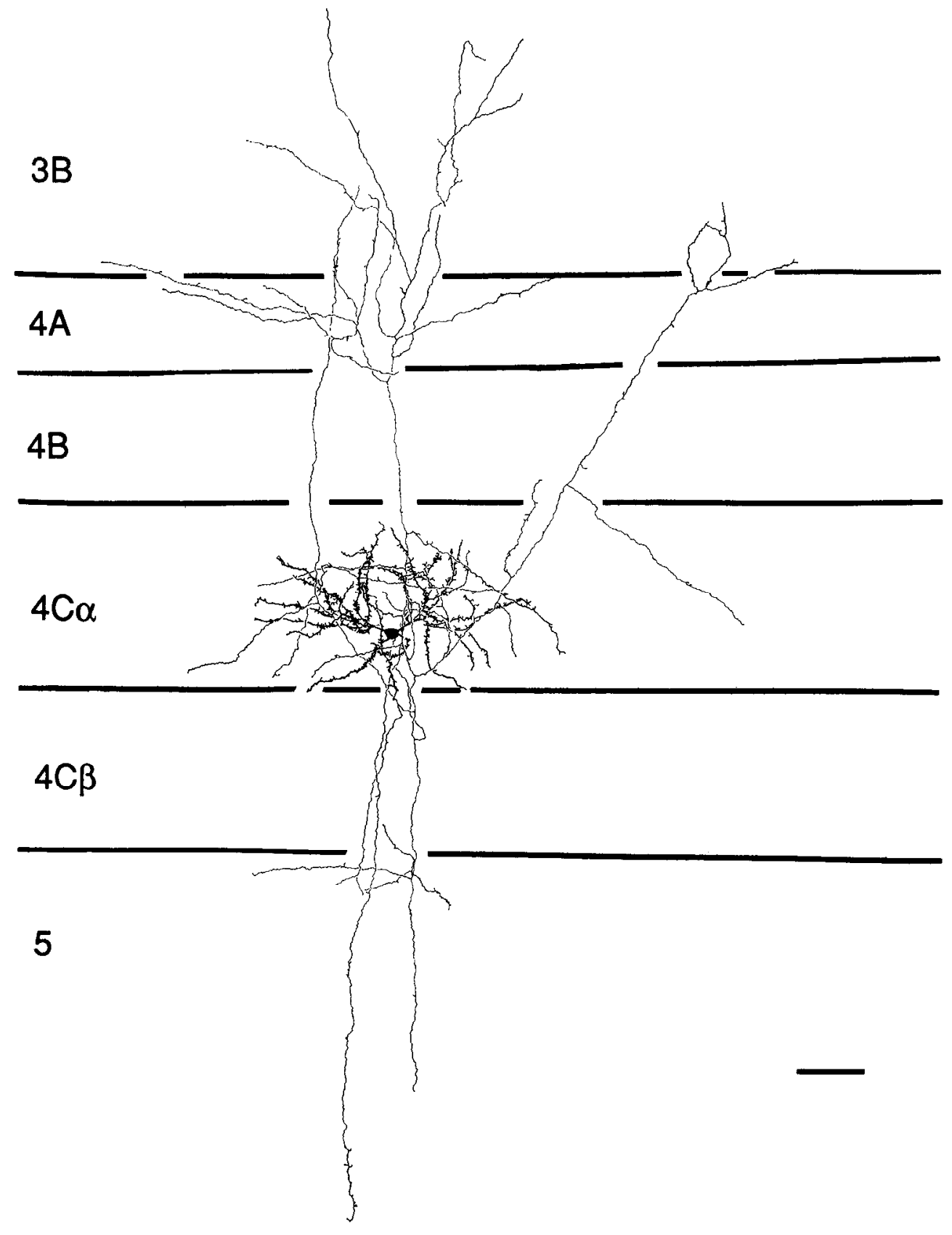

Figure 8. Spiny stellate cell stained in layer $4 \mathrm{C} \alpha$. This cell (which was not near a column boundary) had dense axonal arbors in layers $4 \mathrm{~A}$ and $3 \mathrm{~B}$ but few collaterals in $4 \mathrm{C} \beta$. Unlike the spiny cells in $4 \mathrm{C} \beta$, this cell appeared to have 2 clusters of axon terminals in the upper layers, separated by about $400 \mu \mathrm{m}$. Scale bar, $100 \mu \mathrm{m}$ to explain some of the mixing phenomena that have been described in the region just outside a blob, for example, colorspecific, orientation-selective cells near blob edges.

In these investigations we were primarily concerned with determining whether cells in layer $4 \mathrm{C} \beta$ were constrained by similar types of input (i.e., parvocellular inputs) arising from different eyes. A second important issue, which we did not investigate extensively, is whether dendrites behave differently at the border between different types of inputs, such as magno- and parvocellular inputs. In the visual cortex of the tree shrew, Golgi studies have revealed that the dendrites of many layer 4 stellate neurons are horizontally stratified and seem to reflect the pattern of termination of different types of thalamic inputs (Lund, 1984). An interesting location to examine whether layer $4 \mathrm{C}$ stellate cells distinguish between different types of thalamic inputs would be the afferent-free zone between layers $4 \mathrm{C} \alpha$ and $4 \mathrm{C} \beta$, revealed by labeling both sublaminae with rhodamine. No evidence of a gap has been suggested from Nissl staining, although a cellsparse gap in layer 4C of the tree shrew striate cortex has been noted (Hubel et al., 1977). Cells located in the gap might receive input from both the parvo- and magnocellular geniculate streams, since their dendrites could easily reach into both afferent termination zones. Alternatively, cells might make a choice and direct all their dendrites into $4 C \beta$ or $4 C \alpha$, but not into both. In either case, the anatomical and physiological properties of this zone warrant further investigation.

In addition to the connection to $3 \mathrm{~B}, 4 \mathrm{C} \beta$ cells also had weak connections to layers $4 \mathrm{C} \alpha$ and layer 5 . We did not observe any cells with collaterals within $4 \mathrm{~A}$, as Fitzpatrick et al. (1985) reported. Although we cannot be certain that such cells do not exist, the connection, if it exists, probably does not arise from the spiny stellate cells with connections to $3 \mathrm{~B}$. We are quite 


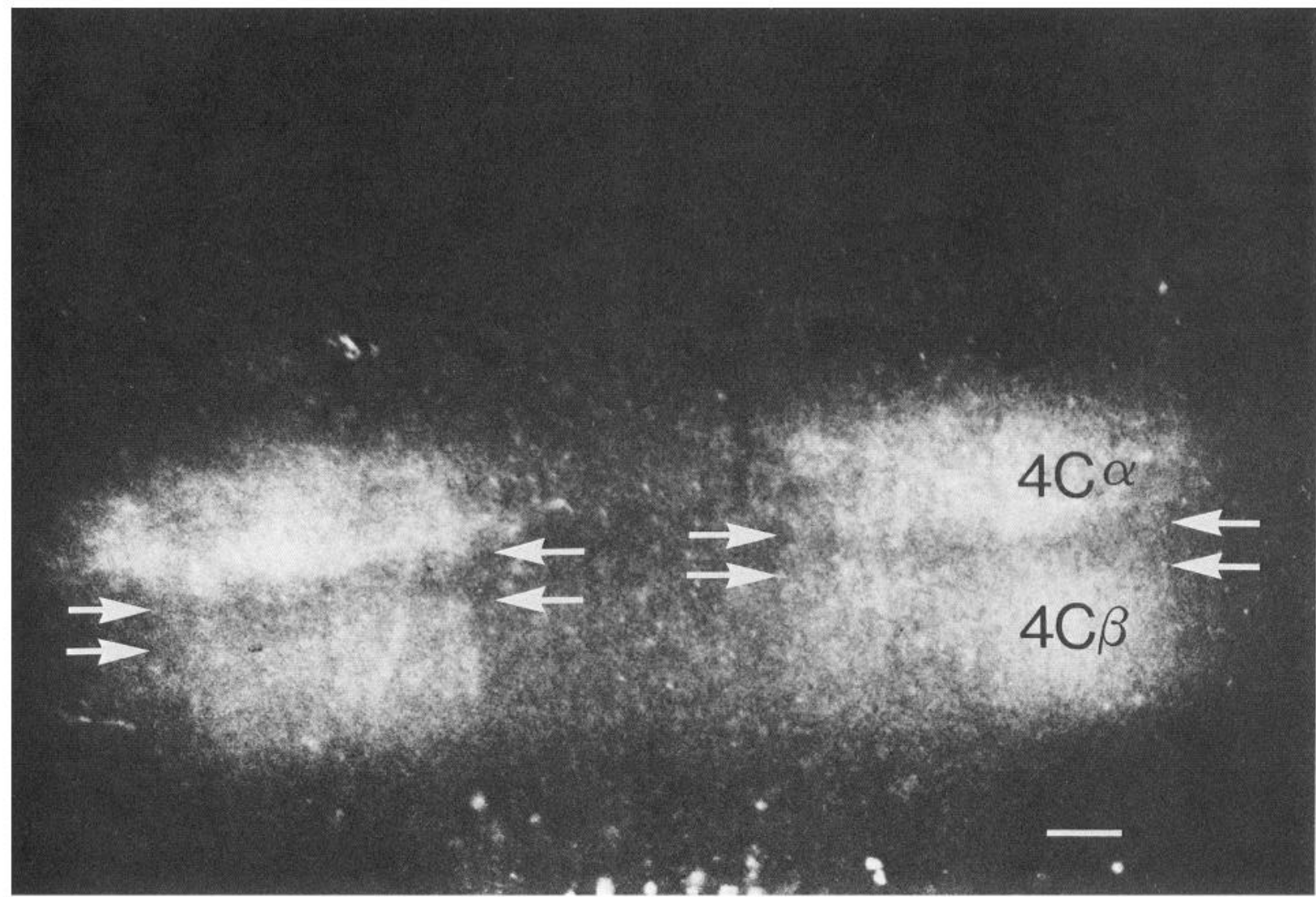

Figure 9. Fluorescent micrograph of a living slice that reveals an afferent-sparse gap between layers $4 \mathrm{C} \beta$ and $4 \mathrm{C} \alpha$. In this experiment, both magnoand parvocellular layers of the geniculate were injected with rhodamine. The resulting pattern, in a thick slice, showed a consistent gap between the 2 afferent termination zones (arrows) about $50 \mu \mathrm{m}$ wide. Scale bar, $100 \mu \mathrm{m}$.

certain that none of our $3 \mathrm{~B}$ connecting cells terminated in or sent collaterals to $4 \mathrm{~A}$

\section{Possible functional roles of intercolumnar connections}

The interactions between ocular dominance columns suggest a possible mechanism underlying the disparity sensitivity of cortical cells. Within the highly refined retinotopic order in layer $4 \mathrm{C}$, adjacent ocular dominance columns have overlapping representations of the visual field, so that as an electrode advancing parallel to the cortical surface crosses an ocular dominance column border, the visual field position of the recorded cells' receptive fields jumps back to a position already covered in the previous column (Hubel and Wiesel, 1977). Thus, the cells that are physically closest and, based on our results, most likely to be synaptically connected (those at column boundaries) may have nonoverlapping receptive fields. A given cell in layer $4 \mathrm{C} \beta$, driven by one eye, could therefore receive inhibitory input from a cell with a nonoverlapping receptive field in the other eye, producing a selectivity for disparity in the recipient cell. A spinefree cell such as the one shown in Figure 2, whose dendrites are confined to one column but whose inhibitory axons arborize densely in the border region of the adjacent column, could be an element in such a circuit. The synaptic interactions we observed across columns could also explain certain psychophysical observations on disparity sensitivity. For example, disparity selectivity is feature independent, so that depth perception can be induced by random dots, and the perception of position in depth of a line of a given orientation can be altered by adjacent dots or lines of different orientations (Julesz, 1971; Mitchison and Westheimer, 1984). This could be explained by the absence of orientation selectivity of cells in layer $4 \mathrm{C} \beta$ that are involved in disparity computations. Another observation is that stimuli presented monocularly can alter the depth perception of a nearby binocular stimulus, and conversely a disparity signal can induce an apparent depth to a monocular stimulus (Westheimer, 1986). The local interactions within $4 C \beta$, across columnar boundaries and within the columns, could contribute to these phenomena.

\section{References}

Blasdel, G. G., and D. Fitzpatrick (1984) Physiological organization of layer 4 in macaque striate cortex. J. Neurosci. 4: 880-895.

Blasdel, G. G., and J. S. Lund (1983) Termination of afferent axons in macaque striate cortex. J. Neurosci. 3: 1389-1413.

Fitzpatrick, D., J. S. Lund, and G. G. Blasdel (1985) Intrinsic connections of Macaque striate cortex: Afferent and efferent connections of layer 4C. J. Neurosci. 5: 3329-3349.

Gilbert, C. D., and T. N. Wiesel (1979) Morphology and intracortical projections of functionally identified neurons in cat visual cortex. Nature 280: 120-125.

Gilbert, C. D., and T. N. Wiesel (1983) Clustered intrinsic connections in cat visual cortex. J. Neurosci. 3: 1116-1133.

Harris, R. M., and T. A. Woolsey (1979) Morphology of Golgi-impregnated neurons in mouse cortical barrels following vibrissae damage at different post-natal ages. Brain Res. 161: 143-149.

Hendrickson, A. E., J. R. Wilson, and M. P. Ogren (1978) The neuroanatomical organization of pathways between dorsal lateral genic- 
ulate nucleus and visual cortex in Old and New World primates. J. Comp. Neurol. 182: 123=136.

Hubel, D. H, and T. N. Wiesel (1968) Receptive fields and functional architecture of monkey striate cortex. J. Physiol. (Lond.) 195: $215=$ 243 .

Hubel, D. H., and T. N. Wiesel (1972) Laminar and columnar distribution of geniculocortical fibers in the macaque monkey. J. Comp. Neurol. 146: $421-450$.

Hubel, D. H., and T. N. Wiesel (1977) Functional architecture of the macaque monkey visual cortex. Proc. R. Soc. London [Biol.] 198: 1= 59 .

Hubel, D. H., T. N. Wiesel, and S. LeVay (1977) Plasticity of ocular dominance columns in monkey striate cortex. Phil. Trans. R. Soc. London [Biol.] 278: 377-409.

Julesz, B. (1971) Foundations of Cyclopean Perception, University of Chicago Press, Chicago, IL.

Katz, L. C. (1987) Local circuitry of identified ncurons in cat visual cortex brain slices. J. Neurosci. 7: 1223-1249.

Katz, L. C., and M. Constantine-Paton (1988) Relationships between segregated afferents and postsynaptic neurons in the optic tectum of three-eyed frogs. J. Neurosci. 8: 3160-3180.

Katz, L. C., C. D. Gilbert, and T. N. Wiesel (1986) Local circuits and ocular dominance columns in monkey striate cortex. Soc. Neurosci. Abstr. 12: 1498.

LeVay, S., T. N. Wiesel, and D. H. Hubel (1980) The development of ocular dominance columns in normal and visually deprived monkeys. J. Comp. Neurol. 191: 1-51.

Lund, J. S. (1973) Organization of neurons in the visual cortex, area 17, of the monkey (Macaca mulatta). J. Comp. Neurol. 147: 455496.

Lund, J. S. (1984) Spiny stellate neurons. In Cerebral Cortex, Vol. 1:
Cellular Components of ihe Ceretral Contex, A. Peters and E. G. Juncs, eds., pp. 255-308, Plenum, New York.

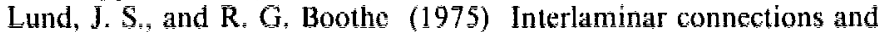
pyramidal neuron organization in the visual cortex, area 17 , of the macaque monkey; $\overline{\mathrm{J}}$. Comp. Neurol, 159: 305=334.

Martin, K. A. C., and D. Whitteridge (1984) Form, function and intracortical projections of spiny neurons in the striate cortex of the cal. J. Physsiol. (Lond.) 353: 463-504.

Michael C. R. (1986) Functional and morphological identification of double and single opponent color cells in layer IVCB of the monkey's striate cortex. Sóc. Neurosci. Abstr. 12: 1497.

Mitchison, G. J., and G. Westheimer (1984) The perception of depth in simple figures. Vision Res. 24: 1063-1073.

Ramón y Cajal, S. (1911) Ilistologie du Systeme Nerveux de l'Homme et des Vertebres (1972 cd.), CSIC, Madrid.

Steffen, H., and H. van der Loos (1980) Early kesions of mouse vibrissal follicles: Their influcncc on dendrite orientation in the developing barrelfield. Exp. Brain Res. 40: 410-431.

Thanos, S., and F. Bonhoeffer (1983) Investigations on the development and topographic order of retinotectal axons: Anterograde and retrograde staining of axons and perikarya with rhodamine in vivo. J. Comp. Neurol. 219: 420-430.

Ts'o, D. Y., and C. D. Gilbert (1988) The organization of chromatic and spatial interactions in the primate striate cortex. J. Neurosci. 8: 1712-1727.

Valverde, S. (1971) Short axon neuronal subsystems in the visual cortex of the monkey. Int. J. Neurosci. 1: 181-197.

Westheimer, G. (1986) Spatial interaction in the domain of disparity signals in human stereoscopic vision. J. Physiol. (Lond.) 370:619629 